\title{
MUJERES JÓVENES EN LA TRANSICIÓN DEMOCRÁTICA: LA COORDINADORA Y LA ASAMBLEA DE MUJERES DE VALENCIA
}

YOUNG WOMEN DURING THE SPANISH DEMOCRATIC TRANSITION: THE COORDINATOR OF WOMEN AND THE WOMEN'S ASSEMBLY OF VALENCIA

\author{
Vicenta Verdugo-Martí \\ Florida Universitaria Grup Cooperatiu (España) \\ ORCID.org/0000-0002-4291-0518
}

Recibido el 28-6-2016 y aceptado el 7-9-2016

Resumen: El presente artículo aborda la participación y militancia en el movimiento feminista valenciano de una generación de mujeres nacidas entre 1947 y 1962, por lo que vivieron parte de su juventud durante la Transición Democrática. A partir de sus testimonios orales, se recogen los primeros contactos con la política y el feminismo, la problemática relación de las doble-militantes con la política partidista y/o sindical, así como la diversidad de grupos feministas que fueron surgiendo en el panorama transicional valenciano. Igualmente, a través de las voces de las jóvenes feministas se narran las experiencias de militancia, la búsqueda de independencia del movimiento feminista respecto a los partidos de la izquierda y el activismo desarrollado por las plataformas feministas Coordinadora de Mujeres y Asamblea de Mujeres de Valencia entre los años 1976 a 1982.

Palabras clave: Mujeres jóvenes, movimiento feminista, Coordinadora de Mujeres de Valencia, Asamblea de Mujeres de Valencia, Transición Democrática.

Abstratc: The present issue deals with the participation and militancy in the feminist movement of a generation of women born between 1947 and 1962 . They lived most of their youth during the democratic transition, their activities were focussed on the Valencian feminist movement, which and through the 
oral sources we can know how these young women started their political and feminism activities, so as the problematic relation-ships due to the double militancy: Political associations and Unions. Also the diversity of women's groups emerged in the Valencian transitional landscape. Besides, through the voices of these young feminists, we approach to their experiences seeking the independence of the movement from the left parties also the activities developed into the: La Coordinadora y Asamblea de Mujeres de Valencia (Coordinator of Women and Women's Assembly of Valencia) between the years 1976-1092.

Key words: Young women, feminist movement, The Coordinator of Valencian Women, The Women's Assembly of Valencia, transition to democracy. 


\section{Introducción}

El presente artículo trata de analizar cuál fue la implicación de las mujeres jóvenes en el movimiento feminista valenciano durante la Transición Democrática, concretamente en la Coordinadora y la Asamblea de Mujeres de Valencia. Es preciso señalar que no nos proponemos hacer un estudio separado relativo a un «feminismo joven». Es más, la categorización de un «feminismo joven» o de organizaciones que lleven este adjetivo con demandas específicas no aparecerá hasta mediados los años ochenta. Si bien en 1979 en las II Jornadas Feministas en Granada se realizó una ponencia titulada «Mujer Joven», no fue hasta 1986 cuando se celebraron las I Jornadas de Mujeres Jóvenes de Euskadi. Tampoco aparece en la documentación de los grupos y plataformas valencianas una auto designación como jóvenes, ni una organización que se identifique explícitamente como tal. Sin embargo y a pesar del «silencio» de la documentación, nuestra hipótesis es que las experiencias vitales de juventud, la edad de las militantes feministas de los años setenta, fue un componente significativo que actuó en el movimiento feminista valenciano interrelacionado con múltiples factores identitarios culturales y político-ideológicos, lo que contribuyó a reformular y condicionar sus discursos, actuaciones y reivindicaciones colectivas.

Para aproximarnos al compromiso de las jóvenes en los feminismos de los años setenta nos centraremos en el análisis de testimonios orales de militantes que estuvieron involucradas en las plataformas unitarias: Coordinadora y Asamblea, que conformaron el movimiento feminista durante la Transición Democrática en el País Valenciano. Para ello, junto a una serie de fuentes orales de recopilación propia, se han utilizado también algunos de los testimonios que pertenecen a los proyectos «Género y militancia de mujeres en los orígenes del sindicato CCOO en el País Valenciano», proyecto realizado por el Archivo José Luís Borbolla del sindicato CCOO-PV, en el que participé en el año $2010^{1}$, y «Memoria del Feminismo en el País Valenciano, 1970-1997» elaborado por Concepción Gisbert Jordá, Dolores Sánchez Durá y M. ${ }^{\text {a }}$ Teresa Yeves Bou² .

\footnotetext{
${ }^{1}$ AJLB CCOO-PV. Mujeres, Trabajo y Militancia Sindical bajo la Dictadura, sobre la militancia de mujeres en los orígenes de CCOO PV (1958-1986). Sánchez; Verdugo; Gómez, 2011..

${ }^{2}$ Gisbert, Sánchez, Yeves, Memoria del Feminismo en el País Valenciano, 1970-1997. [Página web]. 2011.< feministasvalencianas.wordpress.com/> Agradezco a las autoras que me hayan facilitado la transcripción de algunas de las entrevistas.
} 
Para reconstruir genealogías e historizar los feminismos de la Transición, analizaremos experiencias de militancia feminista de mujeres jóvenes, una generación nacida entre 1947 y 1962, por lo que en 1977 tenían entre 30 y 15 años. Partimos de estas fechas al utilizar de manera orientativa la categorización por edades realizada por Judith Astelarra ${ }^{3}$. Según esta autora, esta es la generación de mujeres de la Transición ${ }^{4}$. Mujeres educadas en el franquismo pero que compartieron la experiencia de ruptura con la dictadura ${ }^{5}$. Así, la edad como parámetro que distingue diferentes generaciones, nos ayuda comprender las experiencias femeninas, a insertarlas en determinados contextos históricos-sociales y en universos simbólicos, culturales y familiares ${ }^{6}$.

Desde una perspectiva cualitativa, partiendo de los testimonios de algunas de sus integrantes, realizaremos una aproximación a la conformación del movimiento feminista en Valencia. Para ello se estudiarán «experiencias personales de vida» de mujeres concretas, experiencias que contribuyeron al proceso de concienciación y de formación identitaria en clave feminista ${ }^{7}$. Se trata pues de vivencias subjetivas que podemos interpretar como significantes y expresivas de un conjunto más amplio, teniendo en cuenta que el relato de esas experiencias subjetivas fabrica memorias diferenciadas de mujeres, memorias que son significativas ${ }^{8}$. En este sentido, la utilización de las fuentes orales, su relación con la memoria y los significados del concepto de «subjetividad» interpretados como sujeto individual pero también como sujeto colectivo ${ }^{9}$, permite poder estudiar el feminismo español de los años setenta como un sujeto colectivo problemático y diverso, permite la recuperación de protagonistas del pasado y la revalorización de sus experiencias para comprender y escribir la historia ${ }^{10}$. A la vez,

${ }^{3}$ Astelarra, 2002, p. 4. Establece tres generaciones de mujeres: la generación pre-transición era la que tenía 35 años o más en 1977; la generación de la transición, tenía entre 15 y 34 años y la generación post-transición, menos de 14 años.

${ }^{4}$ Podemos referirnos a esta generación de mujeres de la Transición como parte de una generación histórica. Véase: González Calleja, 2004, p. 224: « .. en circunstancias de cambio rápido y contradictorio las cohortes de edad evolucionan hacia generaciones históricas, que rompen los límites de la convención social para producir movimientos generacionales con identidad propia.»

5 Passerini, 2006, p. 62.

6 Astelarra, 2002, p. 4.

7 Nash, 2013, p. 141.

8 Hernández Sandoica, 2004, p. 39.

9 Passerini, 2006, p. 12.

${ }^{10}$ Llona, 2009, p. 35. 
las fuentes orales nos aproximan a las «memorias históricas y sociales» de los feminismos en la España de la Transición Democrática. Porque es en el interior de nuestro grupo de pertenencia donde construimos nuestros recuerdos, donde conformamos nuestras identidades y del que asumimos sus valores, creencias, símbolos y visiones del mundo ${ }^{11}$.

La dictadura no fue un período monolítico y a partir de los años sesenta los cambios socio-económicos y culturales del contexto desarrollista y las influencias del exterior tuvieron un influjo directo en las generaciones más jóvenes. Una generación de mujeres y hombres que no vivió la guerra civil y, por tanto, estaba menos condicionada por el miedo paralizante de las generaciones de guerra y posguerra. Fueron fundamentalmente las mujeres de esta generación las que conformaron durante la Transición Democrática el movimiento feminista y plantearon una serie de demandas novedosas. En este sentido, M. ${ }^{a}$ Ángeles Larrumbe ha señalado como rasgo característico del movimiento feminista de la Transición su juventud, como una lucha de las jóvenes inconformistas frente al encorsetado mundo en el que se las quería integrar, por lo que se opusieron a él con la firme convicción de cambiarlo ${ }^{12}$. Jóvenes educadas durante el franquismo en un contexto económico expansivo y que accedían a ámbitos como la educación universitaria o el trabajo remunerado, al mismo tiempo que conocían a través del cine, la televisión, los viajes o la literatura todo un repertorio cultural de nuevos modelos de género, a la vez que recibían la influencia de los movimientos revolucionarios del 68, planteándose la necesidad de una transformación relevante en los órdenes cotidianos ${ }^{13}$.

Si la juventud fue uno de los rasgos identificativos del movimiento feminista español de los años setenta, otra de sus características se relaciona con el contexto dictatorial en el que surgió. Mary Nash ha señalado la centralidad de la política y del compromiso antifranquista como un elemento clave en el empuje del feminismo como movimiento social, así como la intersección de escenarios políticos, sociales, sindicales, urbanos y personales que intervinieron en la formación de una identidad compartida y de las respuestas colectivas de las mujeres ${ }^{14}$.

\footnotetext{
11 Halbwachs, 2004, p. 399.

12 Larumbe Gorraitz, 2005, pp. 11-12.

13 Galcerán Huguet, 2008, p. 95.

14 Nash, 2013, pp. 140-141.
} 
Partiendo de estas premisas, los testimonios analizados pertenecen a esta generación de mujeres jóvenes que iniciaron sus compromisos políticos y militancias en el antifranquismo y/o el feminismo a comienzos de los años setenta del siglo XX.

\section{Las jóvenes de la transición: entre la militancia política y feminista}

A continuación se analiza la relación de las jóvenes feministas con las fuerzas políticas de la izquierda antifranquista y la creación en Valencia de organizaciones feministas vinculadas a dichas fuerzas políticas. Igualmente, se describe el surgimiento de organizaciones feministas de carácter independiente, relacionadas con el feminismo radical. Así, nos planteamos la centralidad, a partir de 1975, de la generación de mujeres jóvenes, «la generación de la transición», en el feminismo valenciano y la visibilidad de sus propuestas, a partir de las múltiples organizaciones feministas que se crearon en un contexto en que hasta ese momento solo existía el Movimiento Democrático de Mujeres (MDM), que contaba en su seno con algunas militantes comunistas y de organizaciones femeninas de la Segunda República y la Guerra Civil, entre las más conocidas: Pilar Soler y Rosalía Sender. En este sentido, también se puede hablar de «relevo generacional» en el MDM, a partir de los años setenta, cuando mujeres más jóvenes fueron incorporándose al mismo ${ }^{15} \mathrm{y}$ en cuyo seno comenzaron a plantear que la organización de mujeres recogiera reivindicaciones más específicamente feministas ${ }^{16}$.

La realización de las I Jornadas por la Liberación de la Mujer en 1975 y las desarrolladas en Barcelona en 1976 abrió públicamente los debates sobre la discriminación de las mujeres, inaugurando una nueva ola del movimiento feminista en España, lo que supuso su mayor visibilidad en el espacio público. Desde 1976 los partidos a la izquierda fueron organizando estructuras específicas de mujeres. Por lo que se refiere a los partidos de la izquierda clásica, en la década de los años setenta el impulso dado por el PCE a los movimientos sociales para ocupar el espacio público «ensanchando los límites de la legalidad», conllevó la ampliación de

15 AHPCE, Ref. 226/20. Cop. 24-6-71. Caja 117, carp. 2/2

16 AJLB CCOO-PV, I Conferencia de la Mujer en el País Valenciano. PCPV, abril 1976 (s/s); Véase, Verdugo, 2014. 
las bases de militancia. La entrada en el Partido Comunista de una generación de mujeres jóvenes de distinta procedencia social y formación aportó nuevos perfiles de militancias y nuevos valores culturales más acordes con los ecos sesentayochistas y el deseo de transformación social de los órdenes cotidianos que comenzaban a demandar los feminismos en Europa y EEUU. Mujeres jóvenes que criticaban la invisibilidad de la militancia femenina, así como la jerarquía en las relaciones de género entre los y las comunistas y cuestionaban el «canon identitario» reservado a las mujeres comunistas, a la vez que ponían en práctica un doble compromiso político: la militancia en el PCE y su militancia en el movimiento feminista, lo que no estuvo exento de $\operatorname{conflictos}^{17}$. Así, en 1976, el PCE organizó internamente la Comisión del Comité Central para la Cuestión Femenina abriendo un proceso de discusión en el partido sobre las relaciones entre militancia política y feminismo ${ }^{18}$. Este proceso de autocrítica no resultó fácil, puesto que los conflictos en el seno del partido siguieron existiendo incluso después de su legalización y a pesar de los avances feministas recogidos en la documentación oficial del PCE. La experiencia de algunas jóvenes comunistas nos muestra que la clase seguía siendo el eje prioritario en el análisis de la opresión, mientras que «la cuestión femenina» seguía siendo secundaria y tomada en poca consideración como aparece en el testimonio de Amparo Ferrando, por entonces militante comunista:

«Sí. Sí, y lo que pasa es que en el PCE llevaba yo también mi pelea como todas llevábamos, entre otras cosas era de supervivencia por el feminismo, porque era por supervivencia, te aplastaban (...) Y ya lo de los obreros era para morirse, te quiero decir que a mí la clase obrera «va al paraíso» siempre me ponía de los nervios....» ${ }^{19}$.

Las mujeres comunistas, especialmente las jóvenes, con su doble militancia trasladaban su experiencia al interior del PCE; partidarias del feminismo socialista surgían como una corriente crítica del pensamiento marxista enriqueciéndolo con aportaciones del feminismo radical. Planteaban

17 Véase, Moreno Seco, 2013, pp. 43-60

18 Mundo Obrero. n. $.^{\circ} 42 / 24$ noviembre 1976, p. 8.

19 Gisbert, Sánchez, Yeves. Memoria del Feminismo en el País Valenciano, 19701997. [Página web]. 2011.< https://feministasvalencianas.wordpress.com/amparo-ferrando > $[2 / 12 / 2015]$ 
que la lucha feminista debía ser paralela a la lucha por la democracia y el socialismo ${ }^{20}$.

En un marco de creciente efervescencia política, el movimiento feminista aparecía interrelacionado con las culturas políticas de la izquierda y con el compromiso antifranquista. Como se ha comentado anteriormente, a partir de 1976 surgieron una serie de organizaciones feministas como la Associació Democrática de la Dona ${ }^{21}$ relacionada con el Partido del Trabajo de España (PTE), la Unión para la Liberación de la Mujer con vinculación con la Organización Revolucionaria de Trabajadores (ORT) ${ }^{22}$, mientras las militantes del Movimiento Comunista (MC) ${ }^{23}$ y las de la Liga Comunista Revolucionaria (LCR $)^{24}$ crearon también sus propios frentes de mujeres.

Estas organizaciones de extrema izquierda generalmente estaban formadas por gente muy joven provenientes del ámbito estudiantil y obrero. Compartían un proyecto generacional de rechazo a la sociedad adulta y al igual que ocurría en Europa, reaccionaba contra los presupuestos de su «padre político», lo que en el caso español se concretó en las acusaciones de revisionismo al PCE. Como generación se solidarizaban con la actitud de los y las jóvenes radicales de París, Berlín, Praga, Pekín o Berkeley, interpretando la revolución cultural como parte de un proceso de liberación al que la juventud debía prestar todas sus fuerzas. Así, la extrema izquierda se presenta como el relevo político de la generación anterior a la que consideran acomodada al orden establecido e incapaz de dirigir los cambios rápidos, profundos y globales que necesitaba el mundo y que en España pasaba necesariamente por derrocar el franquismo ${ }^{25}$. El predominio de una militancia de mujeres jóvenes en el seno de estas organizaciones incidió directamente en las demandas de género y junto al total cuestionamiento del sistema político-social y su rechazo de la estructura familiar, posibilitó que las propuestas feministas que realizaban las militantes se asumieran con relativa facilidad, vinculando la revolución y la liberación de las mujeres ${ }^{26}$.

\footnotetext{
20 Moreno Seco, 2013, p. 47; Valverde Márquez, 1999, pp. 99-115.

21 Las Provincias, 5 marzo 1977.

${ }^{22}$ La ULM aparece inscrita en el Registro de Asociaciones de Valencia en 1978.

${ }^{23}$ Las Provincias, 3 septiembre 1976.

24 AJLB. CCOO-PV. Doc. Interno LCR, 1977 (s/s)

25 Roca, 1993, p. 93

${ }^{26}$ Moreno Seco, 2013, p. 51
} 
«Bueno yo en el 76-77 es cuando se crea la estructura de mujeres de lo que era el MCE aquí en Valencia. Nuestra procedencia era de la izquierda, la procedencia marxista, pero al mismo tiempo veíamos que el marxismo no daba respuesta a la opresión de la mujer» ${ }^{27}$.

A pesar de una mayor libertad, de un mayor compromiso feminista y de la juventud de su militancia, en estos partidos pervivían actitudes y prácticas tradicionales que reproducían unas relaciones de género discriminatorias, además de anteponer los intereses de la lucha política partidista a las demandas feministas. A partir de las experiencias personales de militancia emerge la sensación de que las reivindicaciones de las mujeres eran secundarias pese al discurso igualitario existente en el seno de los partidos. Como se recoge en el testimonio de Isabel Morant, las militantes sentían que las cuestiones que afectaban de forma más directa a sus vidas cotidianas como el cuidado de los hijos e hijas y el trabajo doméstico no formaban parte de la discusión política, mientras que para las mujeres suponía una doble carga que problematizaba su actividad política.

«...yo solo estuve en el MC siete meses.(...) en la estructura paralela de mujeres empezó a darse una cosa muy interesante, que es que las directrices desde de la dirección se dejaban de lado y las mujeres militantes de los partidos, que llevaban una vida dura porque estaban con la agenda todo el día, tratando de cuadrar trabajo, familia, hijos con la militancia (...) empezamos a hablar de cuestiones privadas (...) que afectaban a nuestra vida en los partidos y que los partidos no eran conscientes de eso» ${ }^{28}$.

Esta problemática también aparece en la documentación interna de la LCR, donde en un dosier sobre el tema de la mujer, se recoge la necesidad de que toda la organización valorara el trabajo de las mujeres para combatir la tendencia existente que consideraba como secundarias las tareas e intervenciones de la militancia femenina ${ }^{29}$.

27 Entrevista Geno Ros, 22 de mayo 2002.

28 GISBERT; SÁNCHEZ.; YEVES. Memoria del Feminismo en el País Valenciano, 1970-1997. [Página web]. 2011.<https://feministasvalencianas.wordpress.com/isabel-mo$\mathrm{rant} />[5 / 12 / 2015]$

29 AJLB. CCOO-PV. Doc. Interno LCR, 1977 (s/s) 
Por lo que se refiere a las mujeres socialistas y desde una vertiente nacionalista, se creó en 1976 el Centre d’Estudis i Acció Maria Cambrils, un grupo de estudio y reflexión compuesto por jóvenes estudiantes y profesorado universitario de ambos sexos. Defendían la doble militancia como vía para la liberación de las mujeres en una sociedad democrática con postulados socialistas. Participaron en las Jornades Catalanes de la Dona con una ponencia sobre Feminismo ${ }^{30}$. No se trataba de una organización en la que predominaran especialmente una generación de mujeres y hombres jóvenes, más bien se trataba de un grupo intergeneracional $^{31}$.

Por otra parte, hay que señalar que el clima internacional de revuelta cultural y política, de rechazo al orden existente protagonizado principalmente por las y los jóvenes entre Mayo del 68 y los años setenta tuvo su expresión directa en la conformación de los feminismos en Europa y EEUU, donde las jóvenes tomaban la palabra y ponían en tela de juicio la trampa del matrimonio, la asignación del papel procreador y de las tareas domésticas y defendían la libertad de las mujeres para disponer de sus cuerpos.

En España esa influencia fue decisiva en el movimiento feminista de la Transición Democrática, un movimiento que se nutrió de numerosos debates y enfoques teóricos, lo que le dotó de una rica diversidad intelectual, de forma que tiene más sentido hablar de feminismos que de feminismo si queremos abordar con precisión toda su complejidad. Conceptos como opresión, sexismo, patriarcado, género y la mujer como clase fueron elaborados en estos años setenta por el feminismo radical, junto a estos, las aportaciones del marxismo, la política contracultural y el psicoanálisis, conformaron una mixtura teórica que dio un contenido revolucionario y político a la cuestión femenina, identificando como centros de la dominación patriarcal esferas de la vida que anteriormente se consideraban privadas. Con estos parámetros teóricos se constituyeron en 1976 en España los Colectivos Feministas, grupos de jóvenes que partían del análisis del feminismo radical y de la teoría marxista, categorizando a las mujeres como una clase oprimida social y económicamente. Defendían la

30 Solbes López, 1992, p. 25.

31 Entre sus integrantes se encontraban Ernest Lluch, M. ${ }^{a}$ Dolores Bramon, Jordi Palafox, Teresa Carnero y Marius García Bonafé, si bien las noticias e información de que disponemos sobre este grupo son todavía muy fragmentarias, actualmente en proceso de investigación. 
militancia únicamente en el movimiento feminista. En esta línea se creó en Valencia el Colectivo Feminista en 1977, que entendía el feminismo como una acción política revolucionaria para subvertir la sociedad machista y capitalista ${ }^{32}$.

En enero de 1976, se organizó el Grupo Terra, uno de los más emblemáticos del feminismo valenciano, compuesto mayoritariamente por mujeres jóvenes, excepto una de sus fundadoras, considerada como «alma mater» del grupo: Presen Sáez de Descatllar que, por edad, pertenecía a una generación anterior. Nacida en 1932, su biografía nos muestra un intenso activismo intelectual, pedagógico y feminista hasta su fallecimiento en el año 2003. El grupo Terra tuvo su origen en un núcleo de mujeres enseñantes que, convocadas por las Plataformas Anticapitalistas ${ }^{33}$, se reunían para hablar sobre cuestiones políticas ${ }^{34}$. A partir de aquí, comenzaron a reflexionar sobre su propia situación como mujeres, su sentimiento de marginación, la sexualidad y la maternidad, su identidad individual y colectiva. Su objetivo era potenciar nuevas formas de relación entre mujeres. Para ello, como aparece en el testimonio de Dolores Juan, leían y debatían sobre textos teóricos del feminismo radical. Defensoras del feminismo autónomo y radical recibían la influencia del feminismo italiano de la diferencia.

«...en Terra llegamos a ser veinte o veinticinco (...) En enero del setenta y seis hubo una reunión más formal (...) Empezamos a reunirnos y entonces así como primera entrega, pues [leímos] El Manifiesto de las Redstockings (...) Entonces dijimos: bueno y lo de las reuniones pues lo hacemos de una forma regular y entonces todas las semanas nos reuníamos, primero en casas particulares, conseguimos luego alquilar un piso (...) Entonces allí pues seguimos leyendo pues: Escupamos sobre Hegel, de Carla Lonzi de la Librería de Milán» ${ }^{35}$.

Se revitalizaron organizaciones relacionadas con el pensamiento libertario como Mujeres Libres, que reapareció en Valencia en $1976^{36}$. Propug-

32 Vindicación feminista, n. ${ }^{\circ}$ 11, 1 mayo 1977, p. 21.

33 Véase: Sanz Díaz, 2002.

34 Entrevista a Presen Sáez Descatllar, 20 mayo 2002.

35 Gisbert, Sánchez, Yeves, Memoria del Feminismo en el País Valenciano, 19701997. [Página web]. 2011.<https://feministasvalencianas.wordpress.com/dolores-juan-limorte/ > [5/1/2015]

36 Vindicación feminista, n. ${ }^{\circ}$ 9, 1 marzo 1977, p. 16-19. 
naban la lucha conjunta entre hombres y mujeres en todos los sectores de la vida social para destruir las estructuras políticas y mentales que existían en la sociedad; se trataba de un grupo reducido de mujeres muy jóvenes mayoritariamente universitarias y que conocían la tesis doctoral de Mary Nash sobre la histórica organización feminista de pensamiento libertario Mujeres Libres.

«Pues fue la primera asociación en la que me integré, yo creo que fue el año 76. En Mujeres Libres la pertenencia fue desde el 76 al $77(\ldots)$. Entonces era una organización muy abierta, donde simplemente lo que se compartía era pues la problemática de las mujeres y era un sitio donde uno se encontraba muy a gusto» ${ }^{37}$.

En diciembre de 1977, se formó el grupo Front, una iniciativa independiente compuesto por jóvenes feministas partidarias de la doble militancia y del feminismo socialista. Consideraban la consecución del socialismo como un objetivo, pero no suficiente para la liberación de la mujer. Se planteaban el feminismo como una alternativa anticapitalista y antipatriarcal. Rechazaban la imagen que la sociedad daba de las mujeres, buscando por medio de la práctica de la autoconciencia unos valores y una identidad colectiva sobre el significado de ser mujer ${ }^{38}$.

Relacionadas con otros ámbitos de intervención feminista se crearon organizaciones de carácter sectorial como el Moviment Feminista Universitari $^{39}$ o la Asociación de Mujeres Universitarias, compuesta por estudiantes de distintas disciplinas y cuya presentación pública se realizó el 8 de marzo de $1976^{40}$. Mujeres Universitarias se concebía como un grupo de reflexión y elaboración teórica.

«Mujeres Universitarias no se declaraba como un grupo perteneciente...o como ala de un partido político, eso no nos gustaba. Lo montamos también como un grupo de reflexión, como un grupo teórico. Por ello alquilamos un piso, porque lo que queríamos era tener un espacio en el cual pudiéramos montar nuestros seminarios, hacer nuestras discusiones, aunque luego nosotras como organización acudíamos a las

\footnotetext{
37 Entrevista M. . Luisa Moltó, 10 de junio 2002.

38 AJLB-CCOO-PV. Doc. Interno Grupo Front. 1977 (s/s).

39 El País, 5 noviembre 1976.

40 Las Provincias, 10 marzo 1976.
} 
Coordinadoras del movimiento feminista (...) Leímos muchas cosas del feminismo teórico del momento $(\ldots) »^{41}$.

De manera paralela, en el entorno laboral, las jóvenes organizadas en el sindicalismo de clase desarrollaron una labor propia dentro de sus respectivas organizaciones sindicales. Denunciaban la incomprensión del movimiento obrero respecto a los problemas de las trabajadoras pero consideraban que la lucha de las mujeres estaba íntimamente unida a la lucha más general de la clase obrera, aunque planteaban que la resolución de la problemática específica de las trabajadoras les correspondía directamente a ellas ${ }^{42}$. No era fácil romper con la dinámica discriminatoria, por lo que estas jóvenes tuvieron que seguir enfrentándose con sus compañeros para conseguir unas estructuras sindicales que realmente fueran representativas de la clase obrera en su conjunto ${ }^{43}$. Al igual que las organizaciones políticas, el sindicato y la militancia sindical eran un espacio de poder y de actividad propiamente masculina, lo que suponía, como cuenta Carmen Arjona, militante de $\mathrm{CCOO}$, que las sindicalistas tenían que insistir para que se recogieran las reivindicaciones específicas de género de las trabajadoras en las negociaciones y convenios colectivos.

«...la necesidad de que las propias mujeres, dentro del sindicato tomáramos conciencia de hasta qué punto teníamos que luchar contra los tíos (...). Pero aquello de «ya viene el coñazo», de que hay que incorporar no sé qué, y ya viene el tal. «No, perdona, es que en la negociación colectiva, en todo hay que introducir...Es que no es el tema de la mujer como la coletilla que se introduce en cada documento, es que tiene que impregnarse en todo... ${ }^{44}$.

A mediados de los años setenta se articularon relaciones entre el movimiento feminista y las mujeres de los sindicatos que acudían a las reuniones de las plataformas unitarias feministas. De tal forma que, a pesar de las diferencias, como narra Auxi Bustamante, militante de CCOO, se encontraban puntos de acuerdo para poder poner en marcha las campañas feministas.

41 Gisbert, Sánchez, Yeves. Memoria del Feminismo en el País Valenciano, 19701997. [Página web]. 2011.< https://feministasvalencianas.wordpress.com/maite-larrauri/ > [5/01/2015]

${ }^{42}$ Valencia semanal, n. $^{\text {o } 74.3 / 10}$ junio 1979, p. 12.

43 Scott, 1989, p. 95.

44 AJLB-CCOO-PV, Entrevista Carmen Arjona, 16 febrero 2004. 
«La asamblea de mujeres (...) Yo creo que sirvió para abrirnos los ojos de alguna manera y plantearte que las cosas pues, constatar opiniones (...) Aprendimos a buscar puntos de unión, a ver como lo hacemos. Aprendimos a caminar en una palabra, a plantear puntos legales que estaban mermando la libertad de las mujeres, el aborto, la Ley del divorcio.» 45

El surgimiento en la escena pública valenciana de todas estas organizaciones feministas supuso la salida a la luz de nuevos debates (únicadoble militancia), nuevos discursos sobre el significado del «ser mujer»y del feminismo, así como nuevas reivindicaciones relacionadas con la vida personal y con los derechos sexuales y nuevas prácticas políticas. Todas estas cuestiones emergerán en el seno de las plataformas feministas valencianas y crearán conflictos recurrentes, rupturas, pero también alianzas puntuales para la puesta en marcha de las campañas feministas.

\section{Coordinadora de Mujeres y Asamblea de Mujeres de Valencia}

Se expone en este apartado la formación de las plataformas feministas valencianas, primeramente en 1976, la Coordinadora de Grupos de Mujeres del País Valenciano y posteriormente, en 1978, la Asamblea de Mujeres de Valencia, lo que supuso la ruptura del movimiento feminista valenciano.

Nuestra hipótesis sobre la ruptura del movimiento feminista valenciano se basa en las tensas relaciones establecidas entre las militantes de los partidos antifranquistas y la continua búsqueda de autonomía de los partidos políticos del feminismo independiente. Esta cuestión lastró el desarrollo de la Coordinadora donde la presencia de la polémica única-doble militancia estuvo presente en todo momento, hasta que en 1978 se produjo la ruptura y se configuró una nueva plataforma: la Asamblea de Mujeres de Valencia. Relacionamos dicha ruptura con factores identitarios de carácter político-ideológico. Es decir, por una parte, con la concepción del feminismo como una opción global y revolucionaria defendida por las feministas radicales, defensoras de la única militancia y por otra, con aquellas organizaciones feministas relacionadas con las culturas políticas de la izquierda y partidarias de la doble militancia.

45 AJLB-CCOO-PV, Entrevista Auxi Bustamante, 10 noviembre 2004. 
En octubre de 1976, a la vuelta de las Jornadas de Barcelona, se decidió la creación de la Coordinadora de Mujeres del País Valenciano ${ }^{46}$, primera plataforma del movimiento feminista que reunió a todas las organizaciones feministas existentes en ese momento. En 1977 la Coordinadora estaba compuesta por unos setenta grupos conformados primordialmente por mujeres jóvenes ${ }^{47}$ militantes en las diferentes organizaciones de la izquierda, que según Isabel Morant, por entonces militante del MCE, abarcaban desde la izquierda clásica a los partidos de la izquierda radical:

«En esos años yo creo que ya muerto Franco, pero muy recientemente muerto Franco, en Valencia se crea la Coordinadora de Mujeres y en ese momento yo soy militante del Movimiento Comunista, acababa de entrar (...) yo fui la representante del Movimiento Comunista en esa Coordinadora de Mujeres, donde habían mujeres del Partido Socialista, mujeres del que entonces era Partido Socialista del País Valenciano, mujeres comunistas, mujeres de la Liga, vamos de todo, mujeres de... ¿cómo se llamaba? mujeres del aquel Partido de los Trabajadores, sobre todo de partidos de extrema, de lo que después se llamó extrema izquierda o izquierda radical.» ${ }^{48}$

La Coordinadora contaba con una comisión para la preparación de las Jornades de la Dona del País Valencià, así como comisiones de coordinación estatal, campañas y actividades sobre anticonceptivos, aborto, adulterio, divorcio, etc ${ }^{49}$. En 1978 establecieron su sede en la Llibreria Dona. El espacio de la librería fue el centro de apoyo e impulso del movimiento feminista en el País Valenciano ${ }^{50}$.

En el seno de la Coordinadora valenciana desde el principio comenzaron a surgir tensiones respecto a la manipulación del movimiento feminista por parte de los partidos políticos. Tanto las feministas políticas como las radicales autónomas denunciaban la brecha de género existente en las organizaciones de la izquierda y la conducta sexista. Algu-

${ }^{46}$ Las Provincias, 16 octubre 1976.

47 Valencia semanal, n. ${ }^{\circ}$ 63/ 11-18 marzo 1979, pp. 26-28.

48 Gisbert, Sánchez, Yeves. Memoria del Feminismo en el País Valenciano, 19701997. [Página web]. 2011.<https://feministasvalencianas.wordpress.com/isabel-morant/ > [10/01/2016]

49 Archivo personal Presen Sáez, Propuesta de funcionamiento para la Coordinadora. 1977. (s/s)

50 Vindicación feminista, n. ${ }^{\circ} 20 / 1$ febrero 1978, p. 19; Vindicación feminista, n. ${ }^{\circ}$ 21/ 1 marzo 1978, p. 14. 
nas de sus integrantes criticaban que en los partidos políticos y en el sindicalismo no existía una voluntad real de poner en marcha una política igualitaria, más bien, según Isabel Morant, las militantes de la izquierda ponían por delante de las propuestas feministas los intereses de sus correspondientes partidos políticos, lo que pronto desembocó en una serie de problemas:

«Bien, allí no recuerdo que hiciéramos mucho feminismo, creo que lo que hacíamos era pelearnos. Y nos peleábamos porque nuestra adscripción partidista nos hacía poner por delante los intereses políticos (...) Bien, entonces recuerdo que en aquella coordinadora empezaron a surgir problemas ${ }^{51}$.

La búsqueda de autonomía del movimiento feminista respecto de las organizaciones políticas se reflejó en las tensiones que rápidamente se polarizaron en torno a la doble o única militancia. Se ponía de manifiesto la pluralidad del movimiento feminista en cuanto a su concepción de la política, reflejando distintas posturas que iban desde la necesidad de renovar el universo político, tanto ideológicamente como en cuestiones de género a la vertiente de un rechazo total de la política a la que consideraban incompatible con los valores feministas ${ }^{52}$. Lo que en muchas ocasiones se tradujo, según Carmen Alborch, en cierta desconfianza, por parte del feminismo independiente, hacia las militantes de los partidos políticos puesto que se entendía que se postergaban las propuestas feministas frente a los objetivos políticos partidistas.

«...Fue una época en la que también se hablaba de la doble militancia, bueno la doble militancia siempre ha estado bastante presente ¿no? (...) Hubo un momento en que sí que había cierta mirada de falta de confianza, a lo mejor..., bueno o de cierta desconfianza, algunas desconfianzas de las mujeres que militaban en los partidos políticos. (...) vivíamos con cierta tensión el que en algunos partidos políticos se decía que primero era la revolución y luego ya vendría el tema de las mujeres o sea que se intentaba postergar (...) esto era algo que estaba presente en los debates (...) Y nosotras siempre teníamos el discurso de

51 Gisbert, Sánchez, Yeves. Memoria del Feminismo en el País Valenciano, 1970 1997. [Página web]. 2011.<https://feministasvalencianas.wordpress.com/isabel-morant/ > [15/01/2016]

52 Nash, 2009, p. 75. 
que había que hacerlo todo junto porque no se podía separar un tema del otro...» 53 .

A pesar de las discrepancias se consiguió celebrar en diciembre de 1977 las I Jornades de la Dona ${ }^{54}$ y comenzar una campaña sobre la igualdad de derechos y contra el adulterio ${ }^{55}$.

Tras continuos desacuerdos, en noviembre de 1978 se produjo la ruptura de la Coordinadora y se decidió la creación de la Asamblea de Mujeres $^{56}$. El movimiento feminista valenciano quedó dividido: por un lado la Coordinadora de Grupos de Mujeres y por el otro la Asamblea de Mujeres de Valencia. La Coordinadora se mantuvo básicamente con las organizaciones de mujeres que militaban en partidos de la izquierda y en el sindicalismo de clase, como el MDM, ULM, ADM, vocalías de mujeres organizadas en Asociaciones de Vecinos, de Amas de Casa, Asociación de Mujeres Separadas y mujeres de diferentes sectores laborales de $\mathrm{CCOO}^{57}$. Partían de los planteamientos teóricos e ideológicos emancipatorios de las culturas políticas de la izquierda, proponían una redefinición de la noción de política que incorporara las aportaciones del feminismo a la lucha por la democracia y con ello la reivindicación de los derechos civiles, políticos y sexuales para la población femenina.

Por su parte, la Asamblea de Mujeres se definía como independiente de cualquier opción política o de partido. En la Asamblea todas las mujeres participaban a título personal, aunque pertenecieran a diferentes grupos feministas o a organizaciones políticas. Defendían un feminismo radical y autónomo en el que los temas relacionados con la sexualidad ocupaban un lugar central. Tenían una postura muy crítica con las organizaciones políticas. Inicialmente, la Asamblea se formó con mujeres que provenían de vocalías de barrios, grupos de Puerto de Sagunto y Gandía,

53 Gisbert, Sánchez, Yeves. Memoria del Feminismo en el País Valenciano, 19701997. [Página web]. 2011.< https://feministasvalencianas.wordpress.com/carmen-alborch/ $>[17 / 01 / 2016]$ 1977.

54 Levante, 6 diciembre 1977; Provincias, 6 diciembre 1977; El País, 13 diciembre

55 Archivo personal Presen Sáez, Carta convocatoria Coordinadora Grupos de Mujeres, 25 enero 1977 (s/s); Las Provincias, 26 febrero 1977; Levante, 20 septiembre 1977.

56 Archivo personal Pilar Blasco, Acta-convocatoria para la Asamblea General. Coordinadora Grupos de Mujeres de Valencia (s/s).

57 Archivo personal Pilar Blasco, Listado Coordinadora de Grupos de Mujeres de Valencia, 1978 (s/s). 
Lloc de la Dona del Distrito Marítimo, Mujeres Abogados, Gabinete Jurídico, Grupos Terra y Aigua, Seminario de Mujeres, y un buen número de feministas independientes a título individual ${ }^{58}$.

\section{Actividades de la Coordinadora y Asamblea de Mujeres de Valencia}

Las actividades y campañas desarrolladas por el movimiento feminista valenciano sacaron a la luz pública toda una serie de problemáticas y cuestiones relacionadas con la vida privada y con la sexualidad, cuestiones que quedaban definidas a través del lema: «Lo personal es político». Pusieron en práctica una agenda feminista dirigida a conseguir una democracia plena y una ciudadanía igualitaria, así como al reconocimiento de una nueva batería de derechos como los derechos sexuales, lo que sucintamente se resumía en lemas como: «Mi cuerpo es mío». En este activismo feminista, la generación de mujeres de la Transición fue clave, puesto que como ya hemos visto en otros apartados fueron las que configuraron mayoritariamente el movimiento feminista valenciano de la Transición Democrática.

Las principales actividades y campañas realizadas por el movimiento feminista en España abarcaron ámbitos legislativos del Código Civil y del Código Penal. El objetivo era desmantelar la legislación franquista que regulaba la vida de las mujeres. Con el fin de coordinar acciones y campañas de ámbito estatal, en 1977 las militantes de grupos de toda España decidieron constituir la Coordinadora Estatal de Organizaciones Feministas del Estado Español. Plataforma con la que el movimiento feminista de Valencia mantuvo contactos a la hora de poner en marcha en el País Valenciano las campañas lanzadas para toda España.

Las primeras actividades de la Coordinadora Mujeres de Valencia se relacionaron con la demanda de la igualdad de derechos, la reclamación de una ley de divorcio, la despenalización del adulterio, del aborto y de los anticonceptivos, así como una amnistía total en clave feminista ${ }^{59}$. Lo que representaba una ruptura total con la dictadura y una profunda transformación del sistema legislativo franquista ${ }^{60}$.

58 Valencia semanal, n. ${ }^{\circ}$ 63/ 11-18 marzo 1979, pp. 26-28, p. 27.

59 Archivo personal Presen Sáez, Coordinadora Grupos de Mujeres del País Valenciano, 25 enero 1977 (s/s); Archivo personal Presen Sáez, Manifiesto Coordinadora Grupos de Mujeres del País Valenciano, enero 1977 (s/s).

${ }^{60}$ Nash, 2007, p. 172. 
La reivindicación de la despenalización del adulterio y el amancebamiento fue una constante, el caso más seguido por la Coordinadora de Mujeres de Valencia fue el juicio contra Bienvenida García, acusada de adulterio en $1977^{61}$. Isabel Morant, miembro de la Coordinadora de Mujeres, narra cómo se concentraron frente al Obispado de Valencia para pedir la nulidad del juicio.

«Empezamos a protestar delante del Obispado, eso también lo recuerdo como gestos que hacíamos delante del Obispado para pedir que estas cosas no fueran así...» ${ }^{62}$

Una de las claves identificativas del movimiento feminista de los años setenta era la reivindicación de derechos relativos a la sexualidad y la reproducción, definidos en el lema: «mi cuerpo es mío». Se trataba de una categoría de derechos relacionados directamente con la liberación sexual como parte de los repertorios contraculturales que recorrían Europa y EEUU, como manifestación de la rebeldía juvenil de la década de los años sesenta y setenta ${ }^{63}$. Las feministas, integrantes de esa generación joven, rebelde y transgresora, defendían la libertad sexual. Rompían con las normas y convencionalismos del orden moral burgués y patriarcal. Planteaban la separación de la sexualidad y la maternidad, reclamaban la despenalización y gratuidad de los anticonceptivos, así como información sexual y el derecho a interrumpir voluntariamente el embarazo, para poder decidir una maternidad responsable.

Consecuentes con este ideario, tanto la Coordinadora como la Asamblea de Mujeres de Valencia, desde sus inicios, organizaron grupos especializados educación sexual e impulsaron la creación de centros de planificación familiar accesibles a las mujeres de los barrios. Estos cursillos se difundían a través de las Vocalías de Mujeres. En estas actividades, el asesoramiento de jóvenes profesionales y/o estudiantes universitarias tuvieron un papel fundamental. Consuelo Catalá, una joven universitaria de Medicina, que pertenecía a la Asamblea de Mujeres, cuenta cómo se organizaban para realizar charlas en las Asociaciones de

61 Las Provincias, 30 marzo 1977.

62 Gisbert, Sánchez, Yeves. Memoria del Feminismo en el País Valenciano, 19701997. [Página web]. 2011.<https://feministasvalencianas.wordpress.com/isabel-morant/ > [20/01/2016]

${ }^{63}$ Otero Carvajal, 2008, p. 49-68. 
Vecinos y consultas sobre planificación familiar ante la falta de información de las mujeres sobre temas relacionados con la sexualidad y la planificación familiar.

«Entonces eso te hacía, pues yo que sé que cualquier compañero que..., pues te ibas al barrio, hacías una charla o sea que teníamos mucha concienciación de lo que era salir del núcleo de la Universidad (...) Entonces yo creo que nosotras hicimos acercamientos a las Asociaciones de Mujeres de Vecinos, hacíamos iniciativas, pues eso de centros de Planning o de dar consultas» ${ }^{64}$.

Así, en Valencia se crearon entre los años 1976-1979 varios centros de orientación y planificación familiar ${ }^{65}$. Además, el contacto con grupos como el Movimiento de Liberación del Aborto y Contracepción (MLAC) supuso la formación de personal especializado en Valencia, que se dedicó a practicar abortos clandestinamente. Se creó un entramado organizativo feminista dedicado a la planificación familiar y al acceso a poder abortar en condiciones de clandestinidad. La información se transmitía mediante redes entre la militancia feminista, organizaciones de la izquierda y el movimiento vecinal ${ }^{66}$.

En un contexto de alta clandestinidad, ya que el aborto era delito en el Código Penal, la solidaridad con las once acusadas de haber abortado, cuya causa se recogió en el Proceso de Bilbao en 197967, supuso una campaña permanente por la despenalización del aborto que abarcó desde 1979 a $1983^{68}$. Auxi Bustamante, militante de CCOO y participante en la Asamblea de Mujeres, recuerda las movilizaciones que se emprendían y la presión que debían realizar para que el sindicato secundara estas movilizaciones.

«Yo recuerdo pues el tema de los juicios de Bilbao que se plantearon diversos tipos de movilizaciones, costaba muchísimo al sindicato que apoyara o que acudiera. (...) todo el tema de la lucha por el aborto, yo creo que hasta ese momento no se había planteado abiertamente y

${ }^{64}$ Entrevista Consuelo Catalá, 10 marzo 2005.

65 Valencia semanal, n. . 3/ 24-31 diciembre 1977, pp. 32-34.

66 Valencia semanal, n. ${ }^{\circ}$ 94/ 4-11 noviembre 1979, pp. 6-9, pp. 6-7

67 El País, 3 octubre 1979.

68 Archivo personal Presen Saéz, 11 Mujeres en el banquillo por no tener 40.000 pesetas para abortar en Londres. Coordinadora y Asamblea de Mujeres, octubre 1979 (s/s). 
eso fue socialmente como un revulsivo (...) las mujeres tenían situaciones muy malas...» 69

En la dinámica de funcionamiento de las plataformas feministas de Valencia, es de señalar la tarea de asesoramiento sobre temas de legislación que desarrollaron las jóvenes abogadas de los gabinetes jurídicos feministas. En unos casos colaborando en la elaboración de las reformas legislativas y las demandas laborales y educativas que debían aparecer en la futura Constitución ${ }^{70}$. Amparo Ferrando, abogada del Gabinete Jurídico Feminista, narra su asistencia a la Coordinadora de Mujeres Juristas y los debates relacionados con las demandas a la igualdad que desde el movimiento feminista se reivindicaban en la futura Constitución.

Yo en mi vida creo que he ido a más mesas redondas, más debates, he hecho más escritos y me han pedido más cosas (...). Claro es que como había..., se contradecía el propio artículo de la Constitución, por un lado se consagraba la libertad..., la igualdad, perdón, y se penalizaba la discriminación por el sexo, entre otras, a renglón seguido se consagraba la ley sálica y en defecto de varón solamente podía (...) En fin, ninguna queríamos ser reina, nos la sudaba la monarquía pero era por el modelo social que eso representaba y tal...» ${ }^{71}$

Siguiendo con este mismo testimonio, Amparo Ferrando recuerda cómo desde el Gabinete Jurídico Feminista se especializaron en asuntos matrimoniales: separaciones, la tutela de hijos e hijas y los malos tratos. Considera que en los años setenta el matrimonio era uno de los grandes problemas de las mujeres, por la situación de indefensión que padecían y por los malos tratos que mayoritariamente recibían de sus maridos.

«Nosotras pensábamos defender a las mujeres en todos aquellos cuántos problemas tuvieran ¿no? La gran sorpresa que nos llevamos es que las mujeres en este país el problema mayor que tenían, el más serio y el fundamental era el matrimonio (...) Entonces claro, nos llegaron a especializar en matrimonialistas, eso y malos tratos, esos eran (...)

69 AJLB-CCOO-PV, Entrevista Auxi Bustamante, 10 de noviembre 2004.

70 Vindicación feminista, n. ${ }^{\circ} 25 / 1$ julio 1978, p. 7.

71 Gisbert, Sánchez, Yeves. Memoria del Feminismo en el País Valenciano, 19701997. [Página web]. 2011.< https://feministasvalencianas.wordpress.com/amparo-ferrando /> [22/01/2016] 
Siempre era el marido el que se los propinaba, o sea que se circunscribió el Gabinete Jurídico Feminista a derecho matrimonial en su vertiente penal, malos tratos, y en su vertiente civil que eran las separaciones porque entonces no había ley del divorcio (...).» ${ }^{72}$.

Por otra parte, entre las estrategias puestas en marcha para articular el movimiento feminista y reforzar su identidad colectiva sobresale la conmemoración del 8 de Marzo, Día Internacional de la Mujer. En España, fue a partir de 1976-77 cuando su celebración empezó a adquirir mayor visibilidad frente a la clandestinidad que ocultó este recordatorio durante la dictadura. La Coordinadora de Mujeres se acogió en 1977 a la convocatoria estatal de las organizaciones feministas que declararon «el 8 de Marzo» como «Día de Lucha Feminista ${ }^{73}$. Convocaron una manifestación y lanzaron un manifiesto en el que denunciaban la exclusión social en el ámbito familiar, laboral, educativo y político. Demandaban la amnistía para las mujeres condenadas por delitos específicos de género y para la totalidad de las personas detenidas por delitos políticos, reivindicaban la despenalización del adulterio, de los anticonceptivos y del aborto y denunciaban la violencia machista ${ }^{74}$. Pero las manifestaciones del 8 de Marzo en 1977 y 1978 fueron prohibidas y se produjeron enfrentamientos con la policía ${ }^{75}$. Hubo que esperar a 1979 para que esta fecha se celebrara en un clima de normalización democrática. Este año se incidió especialmente en las reivindicaciones de la despenalización del aborto y la legislación del divorcio, lo que era una forma de comenzar estas campañas. A partir de 1979 esta convocatoria se convirtió en un tiempo de encuentro y celebración específicamente feminista para recordar las luchas de las mujeres a lo largo de la historia. Una jornada que con la influencia de esta generación de mujeres jóvenes adquirió aires lúdicos, festivos y espontáneos que rompieron el rígido protocolo que la clandestinidad impuso a esta celebración durante el franquismo, Charo Altable, de la Asamblea de Mujeres, recuerda el ambiente de

72 Gisbert, Sánchez, Yeves. Memoria del Feminismo en el País Valenciano, 19701997. [Página web]. 2011.< https://feministasvalencianas.wordpress.com/amparo-ferrando > [22/01/2016]

73 Di Febo, 1979, p. 215.

74 AJLB-CCOO-PV, Hoja convocatoria: A todas las Mujeres del País Valenciano. 8 Marzo 1977. Coordinadora de Grupos de Mujeres del País Valenciano (s/s).

75 Las Provincias, 9 marzo 1977; Levante, 9 marzo 1978; Archivo personal Presen Sáez, octavilla, Día 8 de Marzo. Día Internacional de la Mujer Trabajadora. 1978 (s/s). 
reivindicación pero también festivo en las conmemoraciones del 8 de Marzo como una fecha de encuentro entre mujeres.

«Porque manifestaciones que hacíamos sobre el «8 de Marzo», naturalmente que llevaban esas reivindicaciones de igual trabajo igual salario, derecho al aborto, mí cuerpo es mío, no sé, todas esas cosas ¿no? el compartir el trabajo doméstico. Pero también había un ambiente festivo ¿eh? De cantos y..., de cenas y de encontrar digamos lo positivo, lo bonito, el espacio, de encontrarse en un espacio de mujeres (...) donde podías expresarte, libremente.» ${ }^{76}$

Para finalizar podemos decir que si bien existieron diferencias entre ambas plataformas feministas, el esfuerzo fue común a la hora de poner en práctica una agenda feminista que condujera a una democracia plena en la que se contemplara una ciudadanía igualitaria y el reconocimiento de una nueva batería de derechos como los derechos sexuales ${ }^{77}$. Las demandas defendidas por las jóvenes feministas fueron asumidas por ambas plataformas y las campañas se pusieron en marcha conjuntamente más allá de las diferencias que surgieron en algunos de los casos como fue en la campaña a favor del divorcio o la campaña en torno al proyecto constitucional. Lo que supuso desarrollar la capacidad de gestar una identidad colectiva de resistencia como mujeres sujetas a discriminaciones específicas de género ${ }^{78}$. Como recuerda Consuelo Catalá, miembro de la Asamblea de Mujeres, las reivindicaciones unían muy rápido porque eran como la «letra gorda».

«[las reivindicaciones]..., unían muy rápido, porque eran como la letra gorda, claro. ¿Cómo no nos vamos a poder divorciar? es que ¿cómo no vamos a poder abortar? (...) Entonces claro, eso eran cosas que eran ipso facto, o sea no eran..., no era coger la coma o el punto, o sea no (...) por eso te decía que al final nos poníamos de acuerdo, porque nosotras eso lo debatíamos hasta la saciedad, hasta la saciedad, si eso iba a liberar o a esclavizar más a las señoras. Si el divorcio, además, no tenía que tener culpables o sí, o sea hasta la saciedad. Pero luego como era tan evidente, acabamos, Ley de Divorcio, Ley de Aborto, apoyándolo..., y unía.» ${ }^{79}$

\footnotetext{
76 Entrevista Charo Altable, 24 de abril 2002.

77 Valencia semanal, n. ${ }^{\circ}$ 63/ 11-18 marzo 1979, pp. 26-28, p. 28.

78 Nash, 2013, p. 141.

79 Entrevista Consuelo Catalá, 10 marzo 2005.
} 


\section{A modo de conclusión}

El movimiento feminista de los años setenta se nutrió de una generación de mujeres jóvenes que, pese haber sido educadas en el franquismo, rompieron con él y cuestionaron los valores tradicionales y los roles de género a los que estaban destinadas. Pertenecen a lo que se ha denominado como la «generación de la Transición». Los testimonios recogidos nos hablan de experiencias vitales de juventud, a pesar del «silencio» de la documentación y las fuentes escritas y a pesar de que estos grupos y plataformas no se auto designaban como «jóvenes». Sin embargo, podemos decir que, a partir de 1975 esta generación de mujeres jóvenes desarrollaron una intensa labor organizativa en el feminismo valenciano con la creación de múltiples organizaciones feministas, donde hasta ese momento solo existía el Movimiento Democrático de Mujeres. Esta generación se alimentó de la «revolución cultural» de los años sesenta y se caracterizó por su alto nivel de politización y relación con las organizaciones de la izquierda antifranquista y con sus ideales emancipatorios. Unas relaciones no exentas de conflicto que conllevaron la elaboración de nuevos discursos feministas que partían de la teorización del feminismo radical e independiente y que en el caso de Valencia contribuyeron a la ruptura del movimiento feminista valenciano en 1978, por las tensas relaciones existentes entre las militantes de los partidos antifranquistas y la búsqueda del feminismo independiente de la autonomía de los partidos políticos, donde la polémica única-doble militancia estuvo presente en todo momento.

Pensamos que dicha ruptura se relacionó con factores identitarios de carácter político-ideológico. Es decir, por una parte, con la concepción del feminismo como una opción global y revolucionaria defendida por las feministas radicales e independientes, defensoras de la única militancia y por otra, con aquellas organizaciones feministas relacionadas con las culturas políticas de la izquierda y partidarias de la doble militancia. Aunque hay que señalar que también este esquema puede resultar simple y que la situación adquirió una mayor complejidad. De hecho, encontramos en la Asamblea de Mujeres, a pesar de ser concebida como una plataforma del feminismo independiente, a mujeres que militaban en las organizaciones de la extrema izquierda. A este respecto, está aun pendiente un análisis en profundidad del contexto transicional que recoja las estrategias políticas de la extrema izquierda para ocupar y rentabilizar espacios en los movimientos sociales frente a la preeminencia del PCE. Un análisis de futuro 
que a lo mejor nos aportaría nuevas claves interpretativas. No obstante, es de resaltar la capacidad que en aquellos momentos tuvo el feminismo independiente valenciano para aglutinar a un nutrido grupo de mujeres en la Asamblea de Mujeres de Valencia.

Las actividades y campañas desarrolladas por las plataformas feministas valencianas sacaron a la luz pública toda una serie de problemáticas y cuestiones relacionadas con la vida privada y con los derechos sexuales. Las demandas defendidas por las jóvenes feministas fueron asumidas por ambas plataformas y las campañas se pusieron en marcha conjuntamente más allá de las diferencias entre el feminismo independiente y las feministas «políticas». Lo que supuso desarrollar la capacidad de gestar una identidad colectiva de resistencia frente a las discriminaciones específicas de género.

Por lo que se refiere a la categorización de un «feminismo joven» con demandas específicas, no fue hasta 1986 cuando se celebraron las I Jornadas de Mujeres Jóvenes de Euskadi. Así, una nueva generación de mujeres jóvenes iniciaba su andadura recogiendo el relevo de las feministas de la Transición e implementando nuevas propuestas y reflexiones sobre el feminismo en un nuevo contexto social, político y económico.

\section{Apéndice: Nota biográfica mujeres entrevistadas}

\section{Carmen Alborch}

Nace en Castelló de Rugat (Valencia) en 1947. Estudia Derecho en la Universitat de València, en la que se doctora y ejerce como profesora titular de Derecho Mercantil. Participó en la Asociación de Mujeres Universitarias y en la Coordinadora y la Asamblea de Mujeres de Valencia.

2. Charo Altable

Nacida en 1945, es licenciada en Historia, maestra especialista en Pedagogía Terapéutica. Militancia feminista en el feminismo independiente, formando parte de la Coordinadora y la Asamblea de Mujeres de Valencia en 1978, su trabajo se centró fundamentalmente en el ámbito del movimiento feminista. Fue una de las fundadoras de la Sociedad Sexológica del País Valenciano (1980) y del grupo «Mujer por la Salud y la Paz» entre los años 1985-86. 
3. Carmen Arjona

Nacida en 1955. Trabajadora del textil, militante del PCE y de CCOO donde desarrolló la Secretaría de Organización de la Unió Comarcal de L’Horta. Entre 1979 y 1982 fue concejala por el PCPV en el Ayuntamiento de Valencia.

\section{Auxi Bustamante}

Nace en Valencia en 1957. Trabajadora del textil. Militante del PCE y de CCOO, participó en la creación de la Secretaría de la Mujer de CCOO-PV. Participaba en la Asamblea de Mujeres de Valencia.

\section{Consuelo Catalá}

Nace en Alicante en 1954, inicia sus estudios en la Universidad de Valencia, donde se vincula con el movimiento estudiantil antifranquista, perteneciendo a la Liga Comunista Revolucionaria. Su militancia transcurre paralelamente a su participación en el movimiento feminista. Militando activamente por los derechos sexuales y reproductivos de las mujeres y la reivindicación del aborto. Participó en la Coordinadora y en Asamblea de Mujeres de Valencia.

6. Amparo Ferrando

Nace en Valencia en 1953, estudia derecho en la Universidad de Valencia donde pertenece al movimiento estudiantil y militará en el PCE, se vincula a la Asamblea de Mujeres de Valencia y ejerce como abogada formando como despacho profesional un $\mathrm{Ga}-$ binete Jurídico Feminista que atendía exclusivamente a mujeres.

7. Dolores Juan

Nace en 1945 en Valencia, estudia música y Graduado Social, de profesión administrativa. Participó activamente, desde sus inicios, en el Grupo Terra, trabajando la experiencia propia desde la identidad de las mujeres a semejanza de los grupos de autoconciencia y, en la Asamblea de Mujeres de Valencia.

8. Maite Larrauri

Nace en Valencia en 1950. Estudió Filosofía y Letras y, desde sus inicios, se vincula al movimiento estudiantil antifranquista. En 1975 participó en la creación de la Asociación de Mujeres Universitarias. 
9. M. ${ }^{\text {a Luisa Moltó }}$

Nacida en 1952. Estudió Económicas en la Universidad de Valencia, donde obtiene el doctorado en 1982 y donde ha desarrollado su carrera profesional, actualmente es catedrática de economía aplicada. Desde los años 70 está vinculada al movimiento feminista. Participó activamente en la organización de las primeras jornadas feministas, celebradas, por su mediación, en el Salón de Actos de la Facultad de Económicas de la Universidad de Valencia en 1977, dónde presentó una ponencia desde la Asociación Mujeres Libres, perteneció a Coordinadora y a la Asamblea de Mujeres de Valencia.

10. Isabel Morant

Nace en 1947. Estudia en la Universidad de Valencia, primero magisterio, que comenzará a ejercer y más tarde Historia. Su militancia inicial es nacionalista y el MC. Vinculada a los movimientos de oposición antifranquista, participó a la Coordinadora y en la Asamblea de Mujeres de Valencia.

\section{Geno Ros}

Nacida en 1947. Licenciada en Psicología. Militante del Movimiento Comunista de España (MCE), formaba parte de la estructura organizativa de mujeres del MCE, desde su creación en los años 1976-1977. Desarrolló su militancia fundamentalmente en el movimiento asociativo vecinal en la Asociación de Vecinos de Torrefiel y en la Coordinadora y la Asamblea de Mujeres.

\section{Fuentes}

Archivo José Luís Borbolla. CCOO-PV (AJLB-CCOO-PV) Archivo Histórico PCE (AHPCE)

Archivo personal Pilar Blasco Archivo personal Presen Sáez Archivo personal Vicenta Verdugo Hemeroteca Municipal de Valencia 


\section{Bibliografía}

Astelarra, J., «La nueva realidad de la desigualdad de las mujeres», Papers de la Fundació, n. ${ }^{\circ}$ 135, 2002. p. 3-26.

DI FeBo, G., Resistencia y movimiento de mujeres en España, 1936-1976, Icaria, Barcelona, 1979.

Galcerán Huguet, M., «El Mayo del 68 Francés y su repercusión en España», Dossiers Feministes, n. ${ }^{\circ}$ 12, 2008, p. 77-98.

Gisbert, C.; SÁnchez, D.; Yeves, T., Memoria del Feminismo en el País Valenciano, 1970-1997. [Página web]. 2011< feministasvalencianas.wordpress. $\mathrm{com} />$

GonZÁlez CAlleja, E., «Las jóvenes generaciones contemporáneas. Evolución de los modos conflictivos de participación política», Dossier des Mélanges de la Casa de Velázquez, Nouvelle série, n. 34 (1), 2004, p. 217-240.

Halbwachs, M., Los marcos sociales de la memoria, Anthropos, Barcelona, 2004.

HERNÁNDEZ SANDOICA, E., «Historia, historia de las mujeres e historia de las relaciones de género», en Del VAL VALDIVIESO, M. ${ }^{a}$ Isabel et alií (Coords.), $L a$ historia de las mujeres una revisión historiográfica, Universidad de Valladolid, 2004, p. 29-56.

Jiménez Tomé, M. ${ }^{\text {a J }}$. (Coord), Pensamiento, imagen identidad: a la búsqueda de la definición de género, Universidad de Málaga, 1999.

LARRUMBE, M. ${ }^{\mathrm{a}}$ Á., «El feminismo y la transición española», Laberintos, n. ${ }^{\circ} 6$, 2005, p. 10-13.

LlonA, M., «Los usos de la memoria para el feminismo», Viento sur, n. ${ }^{\circ} 104$, julio 2009, p. 35-42.

Moreno SeCo, M., «Compromiso político y feminismo en el universo comunista de la Transición», Cuestiones de género: de la igualdad y la diferencia, $\mathrm{n} .^{\circ} 8$, 2013, p. 43-60.

Nash, M., Dones en Transició: De la resistència política a la legitimitat feminista: les dones en la Barcelona de la Transició, Ajuntament de Barcelona, 2007.

NASH, M., «Mujeres en Transición: ciudadanía femenina, legitimidad feminista y la creación de una nueva cultura política», en NASH, M.; TORRES, G.(Eds.), Feminismos en la Transición, Grup de Recerca Consolidat Multiculturalisme i Génere, Barcelona, 2009, p. 71-88.

NASH, M., «Resistencias e identidades colectivas: el despertar feminista durante el tardofranquismo en Barcelona», en NASH, Mary (ed), Represión, resistencias, memoria. Las mujeres bajo la dictadura franquista, Comares, Granada, 2013, p. 139-158.

Otero Carvajal, L. E., «La larga sombra de Mayo del 68», Dossiers Feministes, n. ${ }^{\circ} 12,2008$, p. 49-68.

PASSERINI, L., Memoria y utopía, PUV, Valencia, 2006. 
RoCA, J.M., «La izquierda comunista revolucionaria en España (1964-1992)», Leviatán: revista de pensamiento socialista, n. ${ }^{\circ}$ 51/52, 1993, p. 89-117.

SÁnchez, D.; Verdugo, V.; Gómez, A. (Coords), Mujeres, sindicalistas, feministas, CCOO PV, 1956-1982, Fundación de Estudios e Iniciativas Sociolaborales, CCOO-PV, Valencia, 2011.

SANZ DíAZ, B., Rojos y demócratas. La oposición al franquismo en la Universidad de Valencia (1939-1975), FEIS, CCOO-PV, Albatros, Valencia, 2002.

ScotT, W. J., «Sobre el lenguaje, el género y la historia de la clase obrera», Historia Social, n. ${ }^{\circ}$, 1989, p. 81-97.

Solbes LóPEZ, R., Dones valencianes entre el voler i el poder, Difusora de Cultura Valenciana, València, 1992.

VERdugo, V., «El movimiento democrático de mujeres: el compromiso político por una ciudadanía democrática», en Aguado, A.M.; SANFEliú, L. (Eds.), Caminos de democracia. Ciudadanías y culturas democráticas en el siglo XX, Comares, Granada, 2014, p. 115-131.

\section{Financiación}

Este trabajo participa del Proyecto: «Transiciones, movimientos sociales y democracia en el siglo XX. España en perspectiva comparada» (HAR2014-57392-P).

\section{Datos de la autora}

Vicenta Verdugo-Martí (vverdugo@florida-uni.es), profesora doctora en Florida Universitaria (centro adscrito a la Universidad de Valencia). Ha participado en proyectos de investigación sobre represión franquista y sobre asociacionismo femenino en la Transición Democrática. Forma parte del Grupo de Excelencia Prometeo de Estudios Históricos sobre las Transiciones y las Democracias de la Universidad de Valencia. Es autora de "Desmontando el Patriarcado: prácticas políticas y lemas del movimiento feminista español en la Transición Democrática.» Feminismo/s, (2010); "Prácticas políticas y movimiento feminista en el País Valenciano (1976-1982)", en Feminismos y antifeminismos. Culturas políticas e identidades de género en la España del siglo XX, (2011); "El barrio como frente de lucha: mujeres y movimiento vecinal en Valencia durante la Transición Democrática. », en Valencia 1808-2015. La Historia continúa (2015). 
